ward by means of a palate-hook, or, if space permits, the forceps may be guided by the index finger of the opposite hand. 'The hæmorrhage may be considerable, but ceases immediately. Other children, ranging from the ages of four to fifteen, I have found most tractable, and when old enough to comprehend the nature of their trouble and the object of the operation, only too willing to lend their aid.

For the after-treatment of the seat of the vegetations, a mild astringent and detergent wash is all that is required, while the treatment of the complications in the nose or other parts, must be conducted on general principles. There is an unfortunate belief prevailing among the laity, that that bugbear " catarrh" is some incurable disease, and one we must submit to with resignation. Little cognizance is taken of the different varieties of nasal affections, or of the advance that has been made in recent years in the surgical treatment of the catarrhal diseases of this important organ. In typical cases of adenoid vegetations, the symptoms of "catarrh" of the most aggravated form may be present, yet the good effects of treatment are noticeable, even before it is completed; and I think it may be safely said that there is no other disease in the domain of him who confines himself to the upper respiratory tract, the treatment of which is attended with more satisfaction to the operator, or with more permanent relief to the patient.

\section{SEVERE HAMORRHAGE FROM ANTE-PARTUM SEPARATION OF THE PLACENTA, WITH THE INFUSION OF SIXTY-SIX OUNCES OF SALT SOLUTION.}

\section{BY F. B. HARRINGTON, M.D.}

Mrs. H. is twenty-three years of age. She first came under treatment in January, 188j, suffering with a slight endometritis. She became pregnant for the first time in June. There were no unusual signs during pregnancy until February 6th, about a month before the expected time of delivery. At five P. M., on that date, after lifting some small article, she felt a severe pain in the back. This continued for over a half hour, when there was a sudden rush of blood, wetting the clothing. The flow continued until nearly a pint of blood was collected in a basin. She became faint and was put to bed. When first seen at $6.30 \mathrm{P}$. M., a large surface of blood was found upon the bed and the night-dress was soaked up to the waist. The pulse was 78 and of good strength. The pains were strong and nearly constant. The uterus was low down in the pelvis, the cervix was hard and unchanged by the pains and the os was wholly undilated. After much effort the tip of the finger was inserted into the os. For an hour and a half the finger was thus held, and, although little progress toward dilatation was made, the escape of any large quantity of blood from the uterus was prevented.

It was impossible at this time to push a single finger into the internal os. There was no perceptible change in the condition of the cervix. No fotal movements were felt and the unceasing pains prevented the hearing of the fotal heart. This condition of the patient continued until 9.45 P.M., when there was a sudden profuse hæmorrhage which weakened her at once. She

1 Read, by invitation, before the Obstetrical Society of Boston, February $13,1886$. became blanched and the pulse quickly rose to 120 . Immediate emptying of the uterus became absolutely necessary. The finger was again pushed into the os, and the escape of blood from the uterus was prevented.

Dr. Strong, who was sent for, arrived soon after 10 P.M. The patient was etherized at once. The dilatation of the cervix was most difficult. It resembled the virgin cervix rather than that of a woman pregnant for eight months. During the efforts at dilatation the loss of blood was excessive. The sheets having become soaked in blood, three pints by measure were caught in basins. At length a single finger could be made to reach the internal os. A head was felt fixed against this. The pains were incessant. The uterus seemed tonicly contracted, and because of this, and for fear of delay in turning, the membranes were not ruptured. Slowly a second and third finger were introduced by the use of the utmost force. When it became possible to sweep the finger about the lower segment of the uterus, a perfectly smooth wall was met on all sides, showing that the placenta was high up. The rush of blood continued and stood in pools on the carpet. The patient was greatly collapsed; she was colorless, covered with cold sweat and breathing rapidly. All the force that could be used was brought to bear upon the cervix, and just as an incision was about to be made the tissues yielded, and a large rent allowed the hand to be pushed in to the uterus. The membranes were ruptured. There was a small rush of waters. The feet were easily found and the child was quickly turned and delivered, but was dead. When the feet were drawn into sight, the placenta appeared preceding the body of the child. The uterus contracted quickly and well. A subcutaneous injection of whiskey and one of ergot were given at once. Hot water with vinegar was injected into the uterus. A steady flow of blood continued although the body of the uterus was well contracted. A Sims' speculum was inserted but no bleeding point could be found in the torn cervix.

A swab covered with powdered persulphate of iron was inserted several times into the cavity of the uterus, and applied to the cervix. This controlled the hæmorrhage.

The condition of the patient was extremely alarming. Only the flutter of a pulse could be felt in the wrist. The patient was inverted and the legs were bandaged from toes to hips. Subcutaneous injections of ether and whiskey were repeatedly given, but the patient, perfectly blanched and almost pulseless, began to gasp and to toss for breath. It was now forty-five minutes since the birth of the child and the patient was sinking. It was decided to try infusion. The right median cephalic vein was exposed and raised upon a director and a ligature was passed beneath it. $\mathbf{A}$ funnel and a connecting rubber tube and needle were filled with a solution of salt and water. The needle was tied into the vein. Thirty-six ounces of the salt solution were poured into the vein in about twenty-five minutes. The first few ounces brought the pulse back to the wrist, and the tossing and gasping ceased. Within twenty minutes a slight flush could be seen in the cheeks and the lips took on a little color. The pulse fell to 120 and was of fair strength. The patient was perfectly conscious and took stimulants by the mouth.

There was still no loss of blood and the uterus remained hard and small. The color in the cheeks did 
not remain long, but the patient was quiet and seemed to be resting easily. It was now an hour and a half since the birth of the child and the uterus had remained well contracted. All seemed to be going well, when suddenly the uterus was found to be enlarging. At the same time blood appeared trickling from the vagina. The uterus did not become larger than a cocoa-nut, but the hæmorrhage was profuse. Fresh pledgets of cotton with persulphate were crowded into the cervix. 'The vagina was very tightly packed. This was not done however until the uterus had returned to its small size below the symphisis pubis.

It perfectly controlled the hæmorrhage. The sighing and alarm of the patient had returned. She was tossing from side to side. Enemas and subcutaneous injections were given. The heaters were renewed and placed about the patient. The pulse at the wrist was rapid in the extreme, and at times could not be felt. For three-quarters of an hour every effort was made to improve the patient's condition, but she grew steadily weaker. The skin was cold and clammy. The pupils were widely dilated. The patient's mind wandered. Death was imminent. As a last resort it was decided to attempt a second infusion. 'The left median cephalic vein was this time opened. Thirty ounces of the salt solution were added to the circulation in forty minutes. Slowly the pulse appeared at the wrist. It then became constant, though rapid and feeble. 'The patient soon became quiet but was utterly exhausted. The pulse ranged between 150 and 160 and could only be accurately counted at the chest. Six hours later the pulse had fallen to 148 , and was somewhat stronger In twelve hours it dropped to 140. Here it remained, for thirty-six hours, when it fell to 130 . On the three following days it ranged between 120 and 130 .

February 12. Nearly a week has elapsed, and the patient is doing well. 'The prognosis is favorable.

February 13. The patient had a chill and the temperature rose to $105^{\circ}$. She was seen by Dr. W. L. Richardson in consultation. He gave a favorable prognosis.

\section{REMARKS.}

The cause of the first hæmorrhage was an ante-partum separation of the placenta, brought about perhaps by lifting or by old endometritis or by a combination of the two causes.

The cause of the second hæmorrhage was a relaxation of the uterus occurring an hour and a half after the birth of the child.

The labor may be divided as follows:

\begin{tabular}{|c|c|c|}
\hline February 6th. & 5.30 & $\begin{array}{l}\text { First pains. } \\
\text { A flow of blood. }\end{array}$ \\
\hline & 9.45 " & A second large loss of $b$ \\
\hline & $\begin{array}{l}10.10 \text { “" } \\
11.00 \text { “ }\end{array}$ & $\begin{array}{l}\text { Ether. } \\
\text { Child born. }\end{array}$ \\
\hline & 11.45 “ & First infusion begun. \\
\hline Febr & $\begin{array}{rl}12.10 & \mathrm{A.M} . \\
12.45 & \mathrm{a} \\
1.30 & \mathrm{a} \\
2.10 & \mathrm{a}\end{array}$ & $\begin{array}{l}\text { First infusion finished. } \\
\text { Post-partum hæmorrhage. } \\
\text { Second infusion begun. } \\
\text { Second infusion finished. }\end{array}$ \\
\hline
\end{tabular}

Since the labor the stomach has acted well. There has been excessive thirst but no appetite. She has been given liquid foods and stimulants in small quantities at short intervals.

No urine was drawn for eighteen hours after the birth of the child. Then two ounces were removed by the catheter. The amount secreted soon increased.

An analysis of the urine by Dr. Charles Harrington gave the following result, February 8 .
Color $=$ sl. pale. React. $=$ acid. Urophæin $=\mathbf{N}$. Indican $=\mathbf{M}+$. Ulbumen $=$ Normal.

Albumen $=$ trace
Sediment $=$ Free blood and a few hyaline casts.

Instead of an increase of the chloride of sodium, we find it almost absent, the normal amount being from seven to eleven grms. per litre.

Four days later the amount of salt in the urine had more than doubled. 'The packing was removed from the vagina without much difficulty on February 9 th. No hæmorrhage followed. 'The respiration has remained at a low rate, ranging from ten to twelve for four days.

The stitches were removed from the arms on the fifth day. There had been union by first intention in both.

A specimen of the patient's blood examined in regard to its richness in red corpuscles showed that there had been a diminution from $4,500,000$ to 1,838 000 per c. m. m. On the 12 th there was a farther decrease to $1,824,000$, and on the 13 th to $1,658,000$. This apparent decrease may have been due to the absorption of water by the blood, at a more rapid rate than new corpuscles could be formed. The number of white corpuscles was largely increased.

The breasts have remained perfectly soft and no milk could be pressed from them.

The subject of the infusion of salt solution was first brought to the notice of the writer, by a paper "On the Value of Transfusion of Blood and Infusion of Salt Solution in Acute Anæmia," which was read by Dr. O. K. Newell on April 1st, 1885, before the Surgical Section of the Suffolk District Society, and which unfortunately has never been published. The paper was a translation of an article by Professor Mikulicz (Ueber die Bedeutung der Bluttransfusion und Kochsalzinfusion bei akuter Anämie. Weiner Klinik, Juli 1884.

Mikulicz advises a solution made as follows :

$$
\begin{aligned}
& \text { Sod. Chloride } \quad 60=3 \text { iss } \\
& \text { Sod. Bicarb } 10=\text { grs. } x \\
& \text { Aq. Distillat } 1000 \quad 0=0 \mathrm{ii} \leftarrow
\end{aligned}
$$

This should be raised to about $100^{\circ} \mathrm{Fah}$.

From a pint to three pints can be used. The utmost care should be used that no air shall enter the circulation.

The median cephalic vein can be most conveniently used. The vein should be dissected out and the needle tied into it.

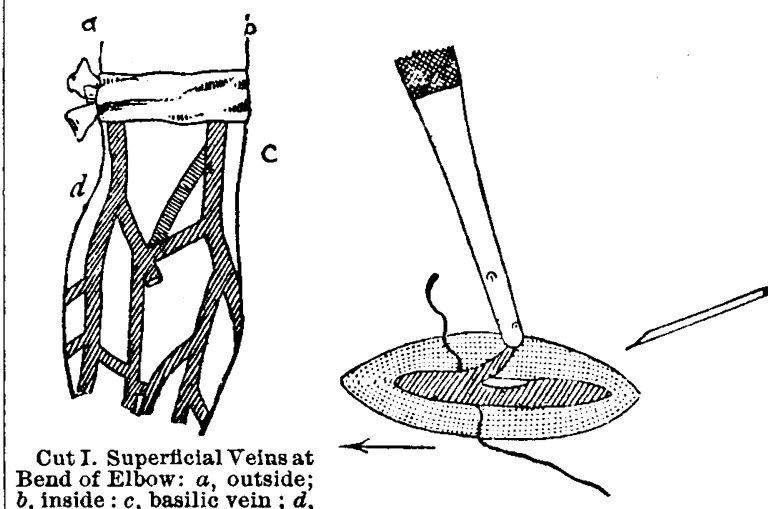

Bend of Elbow: a , outside $b$, inside : $c$, basilic vein ; $d$ cenhalic yein.

Cut II. Method of inserting needle. 


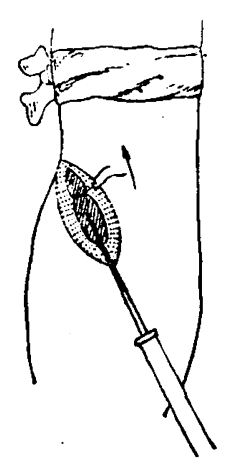

Cut III. The needle in position. The arrow indicates the
direction of the direction all other means had failed. Should February 28th. The patient is doing well. 'The prognosis is favorable.

There was progressive anæmia until Feb. 18th when the red corpuscles had diminished to 1,180,000. After this time they began to increase, and on Feb. 28th reached $2,040,000$ per c. m. m.

\section{REPOR'T ON RECENT PROGRESS IN THORACIC DISEASE. \\ BY F. C. SHATTUCK, M.D.}

CONSEQUENCES OF NARROWING OF THE MITRAL VALVE WHEN OCCURRING IN CHILDHOOD.

The following is a portion of a short article by Dr. Wilks. ${ }^{1}$

"In various ways the effects of heart disease are different as occurring in the growing child and adult. After a marked endocarditis in the child, resulting in thickening and narrowing of the mitral valve, there may be observed great enlargement of the left auricle, with hypertrophy of the right side, becoming sometimes so great as to cause bulging of the chest. In these cases the pulmonary artery partakes of the hypertrophy of the ventricle, and is often found thicker than the aorta. Many years ago, when demonstrating this condition, I used to teach that in all probability the second sound of the heart was produced more by the pulmonary than by the aortic sigmoid valves, and this was before I became aware of the clinical fact pointed out by Skoda that the second sound was more accentuated over the pulmonary orifice in mitral disease. But in cases where there has been no history of endocarditis, although it might probably at one time have been present, where the valves have become contracted without much thickening, and therefore retained their efficiency, these secondary effects do not and need not occur. It is evident that the whole of the blood of the body coming back to the lungs and then passing again to the left side, is measured by the size of the mitral orifice. If this be small, the blood passing through it is diminished in quantity and it becomes a guage of the reduced circulation. The left ventricle is therefore small, and the whole heart correspondingly diminished in size. The lungs are small as well as the chest, and the respiratory process correspondingly lowered, and with

1 Lancet, 1886, 1,6 . this, probably the whole body is impoverished; at all events, the organism is working with a diminished amount of blood. I admit that these simple cases of narrowing are exceptional, for most frequently with the contraction there is some thickening which in course of years manifests itself by symptoms denoting an imperfection of the valve.

"It is, however, the exceptional cases to which I wish to draw attention, those in which the mitral orifice, when narrowed, acts first by producing a diminished stream of blood, the amount in the system being measured by the small mitral orifice, and then, as before said, by a shrinking of the other parts of the circulatory system. During the present year I have seen two such cases on the post-mortem table. One was that of a woman of middle age who had died of some longstanding disease of the brain. In her body was found a very small mitral aperture, admitting only the point of the finger, but having its edges pliable and in every way efficient as a valve. The ventricle was very small and the whole heart was diminished in size, proving that no obstruction or regurgitation had occurred in the mitral orifice. The lungs were not indurated, nor did they show in any way the congestive conditions so well known in heart disease when the blood has been impeded in its course, nor did the other organs display any indication whatever of analogous congestive processes. A very intelligent student expressed his surprise at the absence of the well recognized conditions usually met with in obstructive mitral and other valvular diseases, and that there was not the slightest appearance in the body suggestive of stenosis of the valves of the heart. My answer to him was that there was no disease ; the mitral orifice was smaller than natural, but an effective valve. The contraction had no doubt occurred at an early period of life, and so reduced the amount of blood, of which it was the guage; that the whole heart became in consequence reduced in size, and an entirely new state of things set up. This condition is very different from what occurs when a person is full grown and becomes the subject of a stenosed mitral valve, but even then the prolongation of life is due probably in some measure to the reduced amount of blood in the system."

\section{DROPSY IN MITRAL STENOSIS. 2}

Dr. Broadbent in the course of an admirable article on mitral stenosis remarks on and explains the relative infrequency of dropsy in the above condition. He says: "Another fact which has been impressed upon me, in the course of my observation of the various forms of heart disease, is the late stage at which general dropsy supervenes in uncomplicated mitral stenosis. Not unfrequently the subjects of it are free from œdema at the moment of death, and very commonly it is absent when the symptoms arising from the condition of the heart are most urgent ; it may-set in suddenly after these have lasted for some time. Ascites, again, may occasionally be present independently of œdema, or it may persist after œedema has subsided, occurrences which are altogether exceptional, if not unknown in other forms of heart disease. When dropsy comes on comparatively early, regurgitation will usually be found as well as obstruction, and the incompetence of the valve may not improbably play a greater part in the production of the symptoms than narrowing of the orifice."

3 American Journal of the Medical Sciences, 1886, 1. p. 57. 